\title{
Proposta de Interface para Visualização de Ocorrências em Ambiente Monitorado
}

\author{
Interface Proposal for Event Visualization in Surveilled Environment
}

\author{
> Daniela Kutschat Hanns \\ LabVisual, Faculdade de Arquitetura e Urbanismo \\ Universidade de São Paulo, Brasil \\ dk.hanns@usp.br
}

\begin{abstract}
O presente artigo apresenta resultados parciais de pesquisa relacionada ao desenvolvimento de ambientes interativos em arte-tecnologia que reúne aspectos voltados ao mapeamento de ambientes para gestão ambiental (fluxos, energia, temperatura, ruído) e aspectos voltados a formas de apreensão da informação (cognição) a partir de componentes não exclusivamente visuais. O artigo será dedicado à apresentação da interface de visualização de ocorrências em ambiente monitorado em desenvolvimento para o ambiente.
\end{abstract}

Keywords: arte-tecnologia; ambiente interativo; gestão; monitoramento; affordance

\section{Introdução}

Encontramo-nos, cada vez mais, em ambientes que reúnem um misto de propriedades físicas e digitalmente mediadas. Nas últimas décadas, infra-estruturas de tecnologias de informação e de comunicação têm sido acrescidas às infra-estruturas físicas em ambientes e cidades. As possibilidades de imersão em mundos virtuais, de justaposição de informaçóes ao espaço físico de pervasividade e ubiqüidade das tecnologias têm sido amplamente exploradas nas artes, no design e na arquitetura e suas repercussóes e impactos também têm sido discutidos em contextos variados.

A pesquisa tem sido realizada no laboratório de pesquisa em design visual (LabVisual) da Faculdade de Arquitetura e Urbanismo da Universidade de São Paulo. A pesquisa envolve: a) o desenvolvimento de uma infra-estrutura tecnológica para um ambiente de uso comum, através da qual podem ser captadas informaçôes sobre o ambiente, os objetos e os usuários (sensoriamento); b) o design de programa para leitura e processamento das informaçóes obtidas (programação); c) o design da informação e de interface de visualização e de tangibilização da mesma; d) um método de projeto com fundamentação artística, científica e tecnológica. O diferencial da pesquisa se dá a partir da abordagem que tem como base uma convergência entre ciência e arte.

Ambientes interativos e a cidade digital são objeto de estudo e especulação desde os primórdios da computação. Com o advento da mesma, surgem estudos da cibernética e reflexóes acerca da simbiose entre homem e máquina (Licklider, 1960), da capacidade de ampliação da mente e das faculdades cognitivas (Engelbart, 1962; Goldberg
\& Kay, 1976) e da percepçáo e produção artística (Ascott, 1967). Artistas do contexto acadêmico nacional, como Suzette Venturelli, Silvia Laurentiz, Gilbertto Prado, André Parente, Kátia Maciel, Fernando Iazetta, Giselle Beiguelman, Yara Quasque, Tânia Fraga o grupo SciArts, entre muitos outros, têm realizado experimentos e pesquisa em sistemas digitais e ambientes interativos e explorado, por exemplo, sistemas de realidade virtual, de realidade aumentada, de computação generativa, entre múltiplas possibilidades. Também em contexto acadêmico nacional, arquitetos como Fabio Duarte (2002), Caio Vassão (2008), Santos Filho \& Baltazar dos Santos (2011) e Gabriela Carneiro (2014), têm trazido perspectivas sobre o presente e o futuro da arquitetura e da cidade, seja através de projetos, seja através de reflexão crítica teórica. Teóricos de outras áreas, como da semiótica (Ferrara, 2007), sociologia (Castells, 2009) e filosofia (Zizek, 2012), por exemplo, têm refletido sobre o mundo contemporâneo e o substrato tecnológico que o permeia. Essas pesquisas e visóes são fundantes para o projeto e o artigo proposto. Da mesma forma, uma perspectiva voltada ao design de ambiente para monitoramento e visualização de ocorrências em tempo real (Manovich, 2013) não pode ser desconsiderada.

Entende-se o espaço escolhido para a realização do experimento de monitoramento e visualização de fluxos, ruídos, gasto de energia, atividade de máquinas e ocupação humana como um espaço vivo e de acontecimento. Parte-se da hipótese que nesse ambiente (uma sala comum de pesquisa) muitas vezes não se tem consciência de uma ecologia de ocorrências que podem impactar no próprio ambiente ou em outros ambientes e que um sistema de visualizaçáo das 
ocorrências pode auxiliar os usuários a percebê-los e, eventualmente, induzi-los a comportamentos. Parte-se, igualmente, da hipótese que a experiência pode ser acionada por fenômenos e vivência estética.

A percepçáo dos vários eventos pode, portanto, ser ativada de forma convencional estática (gráfica e visual) e ou dinâmica para apreensão e leitura de valores e ou de estatísticas. Pode também, ser feita de formas mais lúdicas, como por exemplo, audiovisual ou sonora. Por meio do projeto, investiga-se formatos de visualização e tangibilização de informação, a função de cada e como torná-los customizáveis aos usuários para que esse escolha como prefere "sentir" o ambiente e retroalimentá-lo (ajuste de energia, temperatura etc.).

\section{Metodologia e Abordagem}

Freqüentemente edifícios são considerados sistemas fechados ou isolados, isto é, desconsidera-se sua relação com outros espaços construídos e seus impactos em escala maior. Em uma análise de propriedades de fluxos de matéria e energia de edifícios como sistemas sobrepostos que resultam em algo mais complexo que a soma de suas partes, Steven Groak $(1992,22)$ descreve os edifícios como "afetados por, que recebem, filtram, armazenam, processam, despacham e repelem ou descartam entidades físicas". As entidades físicas caracterizam fluxos de entrada e saída de edifícios, como pessoas, máquinas, sistemas de informação e de comunicação, energia eletromagnética, energia cinética e forças, materiais e outros componentes ocasionais.

Fluxos podem ser medidos e monitorados parcialmente ou integralmente para usos e funçóes diversas. Um uso comum de medição de fluxos é relacionado ao conforto ambiental e bem-estar. O corpo- um todo visual, háptico, aural, gustativo e olfativo- é figura central, sensorial e cognitiva que desempenha importante papel na noção geral de conforto e bem-estar. Para o presente estudo, a abordagem ecológica ambiental proposta por James Jerome Gibson (1986) motivou a integração, em ambiente a ser monitorado, dos usuários (agentes vivos) e o seu entorno (environment). Vale ressaltar que o estudo náo se restringe a "medir" o conforto em vários aspectos que envolvem tanto a experiência singular de um ou vários usuários e fluxos mensuráveis no espaço físico; a noção de conforto relaciona-se com uma abordagem fenomenológica de um ambiente que informa assim como é informado em uma perspectiva gibsoniana, na qual "qualquer substância, qualquer superfície, qualquer layout tem uma affordance para o benefício ou prejuízo de alguém" (140, tradução nossa). Nesse contexto, o conforto está relacionado aos sentidos e cognição dos usuários no ambiente em sua dinâmica e interação no mesmo. A base sensorial do conforto está relacionada, por exemplo, tanto ao sentido visual do sujeito quanto aos elementos físicos externos a ele, como a qualidade, a distribuição, matiz e quantidade de luz. Elemento de difícil aferição é o conforto acústico, há vibraçôes e freqüências náo audíveis e, concomitantemente, perceptíveis. Estudos indicam que indivíduos são capazes de tolerar ou ignorar estímulos sonoros prejudiciais durante atividades de alta concentraçáo (Zannin, Diniz e Ferreira, 2003; Paz, Ferreira e Zannin, 2005). Parte do conforto háptico se manifesta através da interaçáo tátil com objetos e do contato com materiais (troca de energia) e troca térmica. Odor e sabor têm sido explorados em sistemas de refrigeração, lojas-conceito e exposiçóes de arte; não foram considerados nesse estudo.

A amplitude de fatores sensoriais está diretamente relacionada ao espaço em que se encontram os usuários, os materiais, inputs e outputs que compóem o entorno. No caso de nosso estudo, tomouse uma sala de pesquisa de $(4.32 \times 3.35)$ metros quadrados e seus pesquisadores como ambiente a ser monitorado. A sala é formada por uma parede fixa e três divisórias móveis, das quais uma compóe um módulo com uma porta e janela fixa que dá para um corredor comum a laboratórios de pesquisa da faculdade. A sala é freqüentada por até cinco pesquisadores, contém armários, mesas e cadeiras de trabalho e está equipada com iluminação central, 11 tomadas, três computadores, duas impressoras, um scanner de mesa, uma máquina de café e um sistema de refrigeração de ar.

A partir da infra-estrutura dada, desenhou-se um sistema de coleta de informaçôes sobre: a) variação térmica; b) sons e ruídos; c) luminosidade; d) gasto de energia elétrica mediante o uso de equipamentos; e) fluxo de pessoas na sala. Em linhas gerais, o ambiente sensorizado serve de base para o sistema de visualizaçâo de ocorrências ao longo do tempo. As ocorrências podem revelar sobre o uso do espaço edificado, sobre potenciais de adaptabilidade, versatilidade, perenidade e ou de obsolescência do mesmo e sobre como e se a variação de correntes de ar, a iluminação natural e a variação de luz e temperatura ao longo do dia, por exemplo, são essenciais para a percepção e o bem-estar dos usuários. Determinou-se que tanto ocorrências mais pontuais, como picos de uso de sala e de equipamentos, como eventos diários e até espaçados e ocasionais seriam mapeados e deveriam ser visualizáveis ou tangíveis. Nessa etapa, visualizaçôes detalhadas e de alta definição não seriam necessários para o experimento.

Para a definição do sistema de visualização, utilizou-se um instrumental variado e baseado em design de visualizaçôes dinâmicas interativas, descrito por Tamara Munzner (2009) e também por Natan Yau (2013). Esse instrumental se desdobrou em classes de açóes que, em algum momento poderiam ser revistas diante de resultados parciais, obtidos em açóes subseqüentes. Em um primeiro momento, por exemplo, se avaliou o tipo de dados que seriam obtidos e opçóes de compor visualizações das ocorrências de maneira rápida e clara e formas de tangibilização de informação envolvendo sentidos além do visual. A definição de operaçôes para a estruturaçáo dos dados em sistema visual gráfico e dinâmico co-evolui com a escolha de plataformas, linguagens e algoritmos em um movimento de retroalimentação e checagem.

\section{Resultados}

Em um primeiro momento, foram explorados sistemas de coordenadas, como o cartesiano e o polar, com variados indicadores visuais (tais como posição, ângulo, comprimento, direção, forma, área e volume). Partiu-se de um sistema baseado em cor para cada um dos componentes: temperatura (vermelho); ruído (azul); luminosidade (cyan); energia (verde); pessoas (amarelo). As variaçóes de cada elemento foram inseridas em dois sistemas gráficos (coordenado e polar) considerando ciclos determinados (dia, hora, minuto, segundo) para cada elemento. Por tratar-se de um sistema 


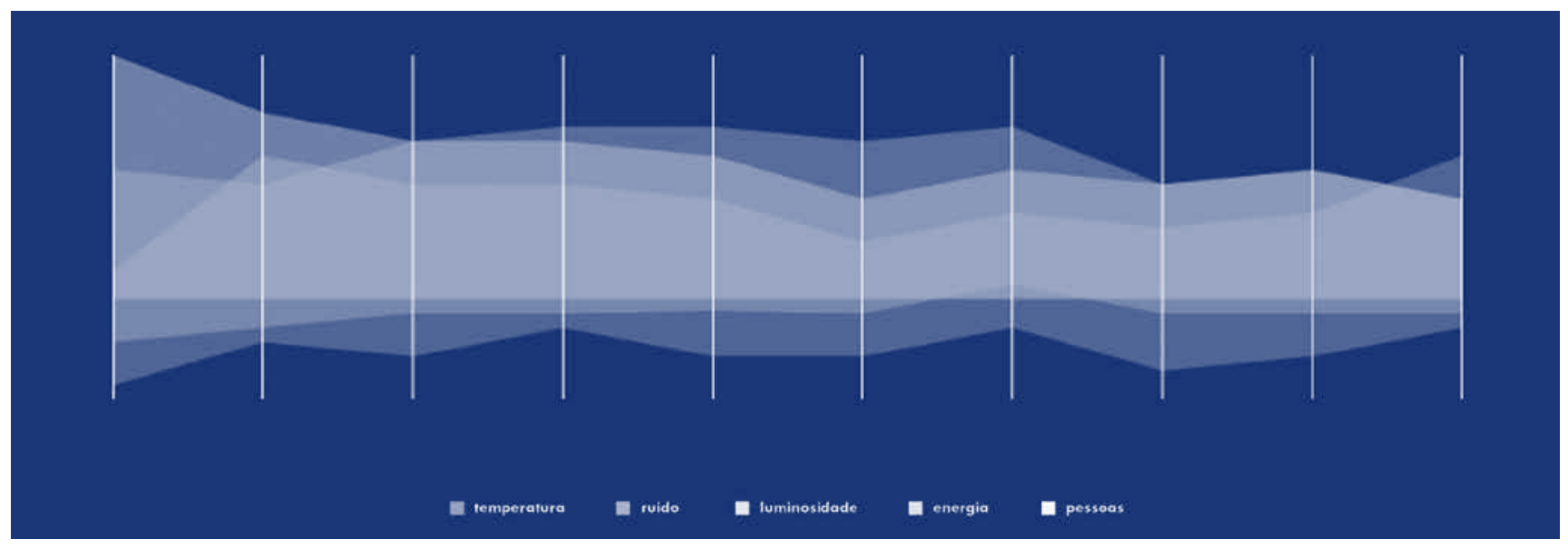

Figura 1: Gráfico de variaçăo de temperatura, ruído, luminosidade, energia e pessoas ao longo de nove dias.

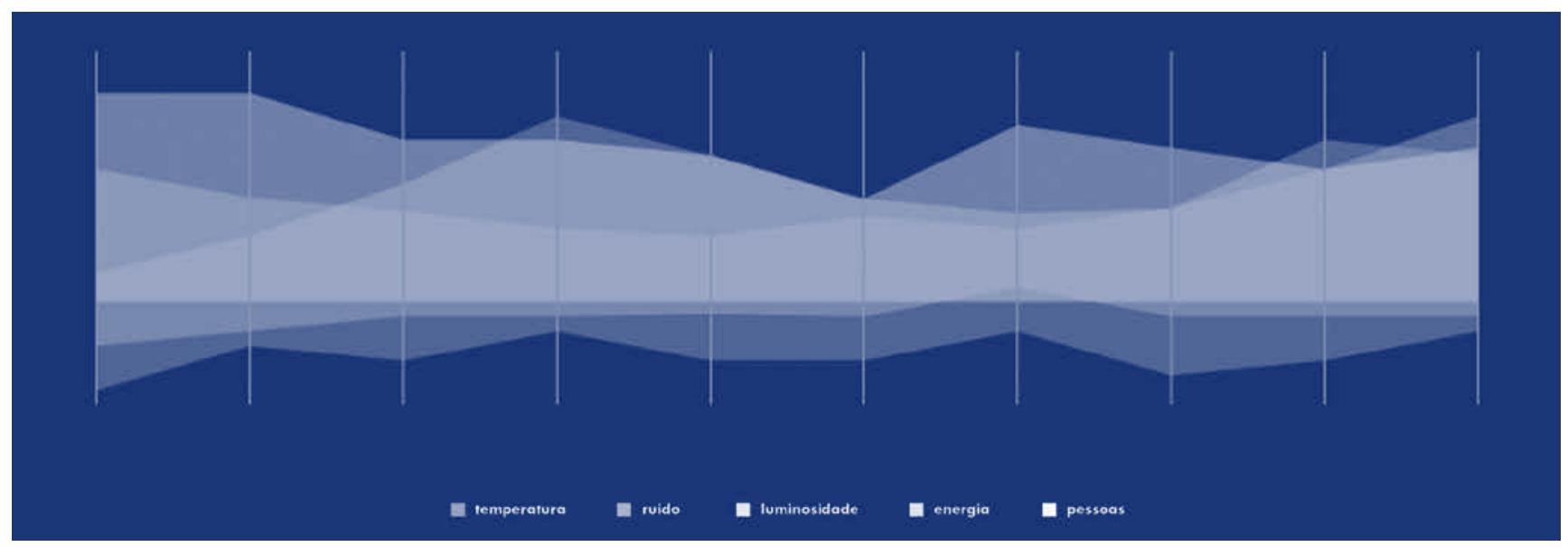

Figura 2: Gráfico de variação de temperatura, ruído, luminosidade, energia e pessoas ao longo de nove horas.

interativo, cada elemento (e cor correspondente) funciona como um canal que pode ser visualizado individualmente e ao qual podem ser acrescidos outros, sobrepostos em transparências, formando camadas a partir de áreas diferentes e compondo, ao mesmo tempo, uma massa comum [Figura 1 e Figura 2]. Outras possibilidades de visualização se mostram importantes para apreciaçôes formais complementares quanto à distribuição dinâmica dos dados sobre variaçóes e fluxos em composição gráfico-visual radial [Figura 3 e Figura 4] e dinâmica, e em uma que resulta na simulação de um terceiro eixo espacial em ascensão em espiral [Figura 5].

As várias simulaçóes, por sua vez, são modelos inspiracionais para um outro tipo de visualização ou tangibilização, imersiva e interativa na qual se visa enfatizar uma fruição ainda baseada em repertório de modelos cognitivos culturais, mas sem explícita referência a códigos, medidas, gráficos e estatísticas, privilegiando a experiência e os sentidos visual, aural e háptico e [Figura 6].

\section{Considerações Finais}

Importante diferencial da pesquisa relatada se deu a partir de uma abordagem metodológica que associa ciência a arte. Estudos sobre cibernética relacionados ao design e à arte, a abordagem fenomenológica de Gibson e produção específica relacionada à arquitetura, ao urbanismo, aos impactos da tecnologia na comunicação e na cidade, fundamentaram a elaboraçáo do sistema e seus componentes a serem monitorados. Um instrumental técnico dedicado ao design da informação e de visualizaçóes interativas que inclui a programação no processo de projeto foi fundamental para o desenvolvimento das visualizaçóes voltadas a uma comunicação direta. As visualizaçóes experimentadas propiciaram a elaboração de um sistema de correspondências entre a) tipo de ocorrência, evolução, ciclo, aparência; b) novas formas de visualização sem referente diretamente identificável entre estímulo (input) e imagem e som (output).

Experimentar ambientes imersivo-interativos desenvolvidos por artistas e arquitetos e a experiência no campo da arte-tecnologia propiciaram, adicionalmente, a estruturaçáo de formas de visualizaçáo e tangibilizaçáo do ambiente a ser desenvolvido em uma próxima etapa. O sistema existente se mostra robusto para a alteração visual e sonora conforme fluxos e ciclos de eventos captados na sala em tempo real. $\mathrm{O}$ ambiente de interação entre agentes físicos, sons e imagens apresenta-se como um espaço de experiência que difere do 


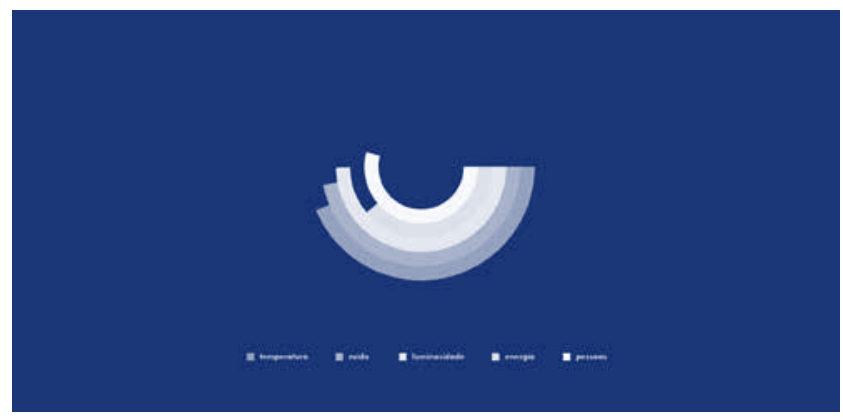

Figura $3:$ Quadro 1 de visualização de ocorrências instantâneas relacionadas à temperatura, ruído, luminosidade, energia e pessoas.

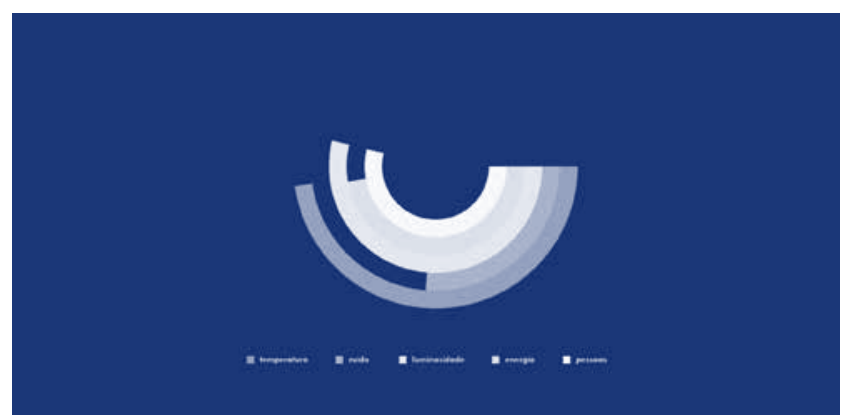

Figura 4: Quadro 2 de visualização de ocorrências instantâneas relacionadas à temperatura, ruído, luminosidade, energia e pessoas.

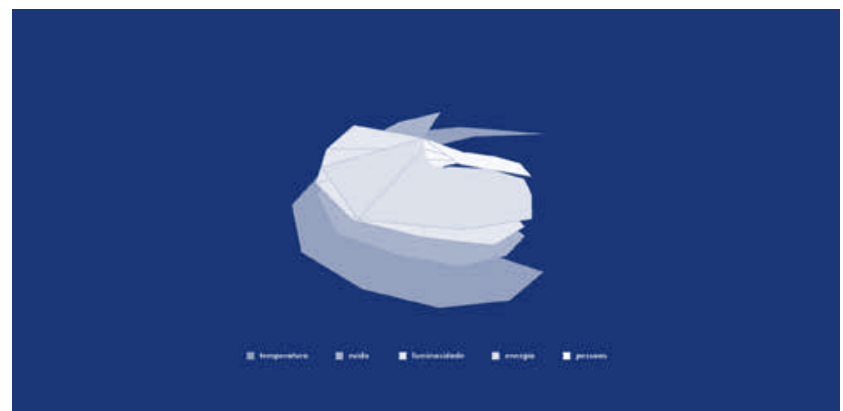

Figura 5: Quadro de visualização simulando eixo de crescimento em espiral.

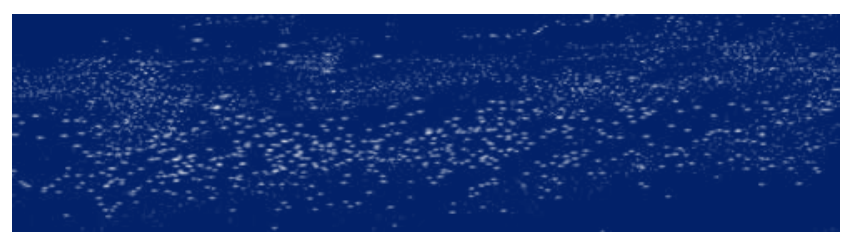

Figura 6: Quadro de modelo derivado do sistema anterior de visualização. primeiro aqui descrito, no qual as visualizaçóes, necessariamente, devem permitir legibilidade e leiturabilidade clara e imediata. Essa outra experiência é entendida como potencial provocadora e desestabilizadora de sentidos, estética.

\section{Referências}

Ascott, R. (1967) . Behaviourist Art and the Cybernetic Vision. In: R. Packer, K. Jordan (Eds.) (2001). Multimedia: from Wagner to virtual reality. New York: W.W. Norton \& Company.

Carneiro, G. P. (2014). Arquitetura interativa: contextos, fundamentos e design. Tese de Doutorado. Faculdade de Arquitetura e Urbanismo da Universidade de Sáo Paulo.

Castells, M. (2012). Networks of outrage and hope: social movements in the internet age. Cambridge: Polity Press.

Domingues, D. (2003). Arte e vida no século XXI. Tecnologia, ciência e criatividade. São Paulo: Edunesp.

Duarte, F. (2002). Crise das Matrizes Espaciais. São Paulo: Perspectiva.

Engelbart, D. C. (1962). Augmenting Human Intellect- a Conceptual Framework. Summary Report. Stanford Research Institute, Menlo Park, California. Disponível em: http://www.dougengel bart.org/pubs/augment-3906.html

Ferrara, L. D’ A. (2009). Comunicação, Espaço, Cultura. São Paulo: Annablume.

Goldberg, A, Kay, A (Eds.) (1976), Personal Dynamic Media," Xerox Palo Alto Research Center, Technical Report No. SSL 76-1.

Groak, S. (1992). The idea of building- thought and action in the design and production of buildings. London: Chapman \& Hall

Licklider, J.C.R. (1960). Man Computer Symbiosis. In: R. Packer, K. Jordan (Eds.) (2001). Multimedia: from Wagner to virtual reality. New York: W.W. Norton \& Company.

Manovich, L. (2013). Software Takes Command. New York: Bloomsbury Academic.

Munzner, T. (2009). A Nested Model for Visualization Design and Validation. Disponível em:http://www.cs.ubc.ca/labs/imager/ tr/2009/Nested Model/NestedModel.pdf

Paz, E. C.; Ferreira, A.; Zannin, P. H. T. (2005). Comparative study of the perception of urban noise. Revista de Saúde Pública. 39, 467-472.

Tufte, E. R. (1997). Visual Explanations: Images and Quantities, Evidence and Narrative. Cheshire: Graphics Press.

Vassão, C. A. (2008). Metadesign Ferramentas, Estratégias e Ética Para a Complexidade - Col. Pensando o Design. São Paulo: Blücher.

Yau, N. (2013). Data Points. Indianopolis: John Wiley \& Sons, Inc.

Zannin, P. H. T.; Diniz, F. B.; Ferreira, J. A. C. (2003). A survey of urban noise annoyance in a large Brazilian city: the importance of a subjective analysis in conjunction with an objective analysis. Environmental Impact Assessment Review, 23,. 245-255. Zizek, S. (2012). Vivendo no fim dos tempos. São Paulo: Boitempo. 